\title{
All the right moves: why in utero transfer is both important for the baby and difficult to achieve and new strategies for
}

\section{change [version 1; peer review: 2 approved]}

\author{
Helena Watson 1,2, James McLaren³, Naomi Carlisle (i)2, Nandiran Ratnavel4, \\ Tim Watts' ${ }^{1}$ Ahmed Zaima5, Rachel M. Tribe², Andrew H. Shennan (D1,2 \\ ${ }^{1}$ Guy's and St Thomas NHS Foundation Trust, London, UK \\ 2Department of Women and Children's Health, School of Life Course Sciences, King's College London, London, UK \\ ${ }^{3}$ Gosford Hospital, Gosford, New South Wales, Australia \\ ${ }^{4}$ Royal London Hospital, London, UK \\ ${ }^{5}$ Kingston Hospital, Kingston upon Thames, UK
}

V1 First published: 13 Aug 2020, 9(Faculty Rev):979
https://doi.org/10.12688/f1000research.25923.1

Latest published: 13 Aug 2020, 9(Faculty Rev):979

https://doi.org/10.12688/f1000research.25923.1

\begin{abstract}
The best way to ensure that preterm infants benefit from relevant neonatal expertise as soon as they are born is to transfer the mother and baby to an appropriately specialised neonatal facility before birth ("in utero"). This review explores the evidence surrounding the importance of being born in the right unit, the advantages of in utero transfers compared to ex utero transfers, and how to accurately assess which women are at most risk of delivering early and the challenges of in utero transfers.

Accurate identification of the women most at risk of preterm birth is key to prioritising who to transfer antenatally, but the administrative burden and pathway variation of in utero transfer in the UK are likely to compromise optimal clinical care. Women reported the impact that in utero transfers have on them, including the emotional and financial burdens of being transferred and the anxiety surrounding domestic and logistical concerns related to being away from home. The final section of the review explores new approaches to reforming the in utero transfer process, including learning from outside the UK and changing policy and guidelines. Examples of collaborative regional guidance include the recent Pan-London guidance on in utero transfers. Reforming the transfer process can also be aided through technology, such as utilising the CotFinder app.

In utero transfer is an unavoidable aspect of maternity and neonatal care, and the burden will increase if preterm birth rates continue to rise in association with increased rates of multiple pregnancy, advancing maternal age, assisted reproductive technologies, and obstetric interventions. As funding and capacity pressures on health services increase because of the COVID-19 pandemic, better
\end{abstract}

\section{Open Peer Review}

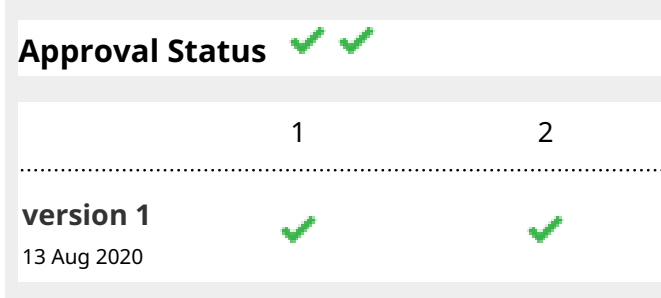

Faculty Reviews are review articles written by the prestigious Members of Faculty Opinions. The articles are commissioned and peer reviewed before publication to ensure that the final, published version is comprehensive and accessible. The reviewers who approved the final version are listed with their names and affiliations.
1. Liisa Lehtonen, University of Turku, Turku,
Finland
Turku University Hospital, Turku, Finland
2. Jennifer Zeitlin, Paris-Descartes University, Paris, France

Any comments on the article can be found at the end of the article. 
prioritisation and sustained multi-disciplinary commitment are essential to maximise better outcomes for babies born too soon.

\section{Keywords}

in-utero transfer, preterm birth

Corresponding author: Helena Watson (helenawatson85@googlemail.com)

Author roles: Watson H: Conceptualization, Data Curation, Resources, Writing - Original Draft Preparation, Writing - Review \& Editing; McLaren J: Conceptualization, Data Curation, Resources, Writing - Review \& Editing; Carlisle N: Conceptualization, Data Curation, Resources, Writing - Review \& Editing; Ratnavel N: Data Curation, Resources, Writing - Review \& Editing; Watts T: Conceptualization, Data Curation, Resources, Writing - Review \& Editing; Zaima A: Conceptualization, Data Curation, Resources, Writing - Review \& Editing; Tribe RM: Conceptualization, Data Curation, Resources, Supervision, Writing - Review \& Editing; Shennan AH: Conceptualization, Data Curation, Resources, Supervision, Writing - Review \& Editing

Competing interests: No competing interests were disclosed.

Grant information: HW is funded by a Guy's and St Thomas (GSTT) and King's College London (KCL) Biomedical Research Council Clinical Training Fellowship Award. The research was supported by the National Institute for Health Research (NIHR) Biomedical Research Centre based at GSTT and KCL and/or the NIHR Clinical Research Facility. The views expressed are those of the authors and not necessarily those of the NHS, the NIHR, or the Department of Health.

The funders had no role in study design, data collection and analysis, decision to publish, or preparation of the manuscript.

Copyright: $\odot 2020$ Watson $\mathrm{H}$ et al. This is an open access article distributed under the terms of the Creative Commons Attribution License, which permits unrestricted use, distribution, and reproduction in any medium, provided the original work is properly cited.

How to cite this article: Watson $\mathrm{H}$, McLaren J, Carlisle $\mathrm{N}$ et al. All the right moves: why in utero transfer is both important for the baby and difficult to achieve and new strategies for change [version 1; peer review: 2 approved] F1000Research 2020, 9(Faculty Rev):979 https://doi.org/10.12688/f1000research.25923.1

First published: 13 Aug 2020, 9(Faculty Rev):979 https://doi.org/10.12688/f1000research.25923.1 


\section{Introduction}

As neonatology has advanced and subspecialised, there has been an impetus to ensure babies have the opportunity to benefit from the relevant expertise as soon as they are born. This is particularly relevant in the initial care of the extremely preterm baby (born $<27$ weeks' gestation) ${ }^{1}$, where evidence shows that care in specialist neonatal intensive care units (NICUs) significantly improves survival ${ }^{2-6}$. In the largest relevant UK study to date, perinatal mortality rates were $19 \%$ higher for the extremely preterm infants born outside NICUs ${ }^{2}$. In utero transfer of the mother to an appropriately specialised neonatal facility prior to birth is the best way to address this access to care. Given current funding pressures and the expense of neonatal services, capacity issues also contribute to the need to transfer mothers and infants between facilities. In the UK, the prevalence of in utero transfer is unknown. It was estimated to be $1.4 \%$ by a Finnish birth register study analysing antenatal care bed days between 22 and 32 weeks' gestation. Even at this relatively low prevalence, given the lifelong health, social, and economic consequences of neonatal morbidity and an obligation to provide equity of expertise to this vulnerable population, the authors believe this is a major public health issue.

Pressures around cot capacity are compounded by rising birth and preterm birth rates, which exceed investment. Since around
$90 \%$ of in utero transfers are for threatened or actual preterm labour, accurate identification of the women most at risk of preterm birth is key to prioritising who to transfer antenatally. This review will explore the evidence surrounding why in utero transfers are important, the challenges faced by clinicians, and the impact on women.

\section{Why do we need in utero transfer?}

The importance of being born in the right facility

There is good evidence that the benefits of being born in a centre with a NICU (also called a 'level 3 neonatal unit' or 'tertiary neonatal unit') are most significant at early gestational ages ${ }^{2-5}$. Every country has specific rules regarding how neonatal care is organised which affect transfer guidelines, particularly around infants at 27-32 weeks' gestation. In the UK, level 3 neonatal units provide care for all babies at gestations after $22^{+6}$ weeks and level 2 units provide care from $26^{+6}$ weeks gestational age (singletons) and $27^{+6}$ weeks (multiple births) providing the anticipated birth weight is above $800 \mathrm{~g}$. Level 1 units usually provide care after $31^{+6}$ weeks gestational age provided the anticipated birth weight is above $1,000 \mathrm{~g}$ (Table 1 and Table 2).

The development of neonatal networks in the UK from 2004 was aimed at ensuring babies who required intensive care after birth were cared for in properly accredited, staffed,

\section{Table 1. Description of categories of neonatal care.}

\begin{tabular}{|l|l|}
\hline Intensive care & $\begin{array}{l}\text { Specialised care for the smallest and most seriously ill babies who require constant care and often mechanical } \\
\text { ventilation to keep them alive. Babies with severe respiratory disease and those who also require surgery will need } \\
\text { this level of care too. }\end{array}$ \\
\hline $\begin{array}{l}\text { High-dependency } \\
\text { care }\end{array}$ & $\begin{array}{l}\text { Care provided to babies who need continuous monitoring. For babies needing non-invasive breathing support, } \\
\text { including receiving continuous positive airway pressure. Babies receiving parenteral nutrition (intravenous feeding) } \\
\text { also need this level of care. }\end{array}$ \\
\hline Special care & $\begin{array}{l}\text { The least-intensive level of neonatal care and the most common. For babies who need continuous monitoring } \\
\text { of their breathing or heart rate, additional oxygen, tube feeding, phototherapy (to treat neonatal jaundice), and } \\
\text { convalescence from other care. }\end{array}$ \\
\hline Transitional care & $\begin{array}{l}\text { Babies who have special care needs (e.g. low birth weight, neonatal abstinence syndrome) but are able to be } \\
\text { managed alongside the mother as the main carer, supported by neonatal and midwifery teams. In some services, } \\
\text { transitional care occurs in the postnatal ward and, in others, in a discreet area or transitional care unit with staffing } \\
\text { from both neonatal and midwifery teams. }\end{array}$ \\
\hline
\end{tabular}

This table was adapted from NHS England service specifications ${ }^{7}$ under the terms of the Open Government Licence v3.0.

\section{Table 2. Definitions of levels of neonatal unit, stratified by the level of neonatal care they provide.}

\begin{tabular}{l|l}
$\begin{array}{l}\text { Level } \mathbf{1} \\
\text { Special Care Unit } \\
\text { (SCU) }\end{array}$ & $\begin{array}{l}\text { Commissioned and staffed to provide care for babies of births after } 31^{+6} \text { weeks' gestation provided the } \\
\text { anticipated birth weight is above } 1,000 \mathrm{~g} \text {. Some Operational Delivery Networks have approved care pathway } \\
\text { where babies born between } 30^{+0} \text { and } 31^{+6} \text { weeks gestation receive initial care in the SCU provided the } \\
\text { anticipated birth weight is above } 1,000 \mathrm{~g} \text { and intensive care is not required. Some SCUs will provide care only } \\
\text { for babies }>33^{+6} \text { weeks' gestation. }\end{array}$ \\
$\begin{array}{l}\text { Level } \mathbf{2} \\
\text { Local Neonatal } \\
\text { Unit (LNU) }\end{array}$ & $\begin{array}{l}\text { Commissioned and staffed to provide care for babies of singleton births after } 26^{+6} \text { weeks' gestation and } \\
\text { multiple births after } 27^{+6} \text { weeks' gestation providing the anticipated birth weight is above } 800 \mathrm{~g} .\end{array}$ \\
$\begin{array}{l}\text { Level } \mathbf{3} \\
\text { Neonatal } \\
\text { Intensive Care } \\
\text { Unit (NICU) }\end{array}$ & $\begin{array}{l}\text { Commissioned and staffed to provide care for all babies from birth, in line with national guidelines and } \\
\text { professional standards, at all gestations after } 22^{+6} \text { weeks. }\end{array}$ \\
\hline
\end{tabular}

This table was adapted from NHS England service specifications ${ }^{7}$ under the terms of the Open Government Licence v3.0. 
and equipped NICUs, and it was recognised even then that it was particularly important in those born extremely preterm (NHS England, 2015). The networks also facilitated repatriation once the neonate was well enough to receive the appropriate level of care locally. Despite this, the most recent UK national cohort (EpiCure 2) revealed that only 56.4\% (1,387/2,640) of births between 22 and 26 weeks' gestation occurred in hospitals with a level $3 \mathrm{NICU}^{2}$. Perinatal mortality rates at this gestation were $72 \%$ in a level 1 unit compared with $53 \%$ in a NICU facility $(P<0.0001)$. Excluding the antenatal deaths, early neonatal deaths were also significantly higher for those delivered at a level 1 versus level 3 facility (33\% versus $23 \%$, $P<0.0001)^{2}$. Another recent UK study reported an increased mortality (odds of death 1.34, confidence interval [CI] 1.02-1.77; number needed to treat [NNT] 20) for those born in a level 2 neonatal unit compared with a level 3 unit ${ }^{8,9}$.

Similar findings have been reported outside the UK. A population cohort study from Victoria, Australia, analysed 541 livebirths (excluding congenital malformations) between $22^{+0}$ and $27^{+6}$ weeks' gestation ${ }^{10}$. They compared those born in a level 3 neonatal unit with those born outside of level 3 units directly. Even excluding infants born at 22 weeks' gestation from the analysis, overall mortality for outborn infants was higher than that of inborn counterparts (adjusted odds ratio [paOR] 2.70, $95 \%$ CI $1.49-4.92, P<0.001)^{10}$. In a Swedish population study of extremely low birth weight infants, mortality was also found to be directly proportional to the level of care received ${ }^{11}$. An international meta-analysis of the effect of perinatal regionalisation reported a $62 \%$ increase in the odds of neonatal mortality for very low birth weight $(<1,500 \mathrm{~g})$ infants born in a non-level 3 facility (37 articles, 104,944 infants) and a 55\% increase in the odds of mortality for very preterm infants $(<32 \text { weeks })^{5}$.

Despite the body of evidence in favour of birth in a unit with appropriate neonatal expertise, not all mothers are accessing this care. In the EPICE population cohort, $12 \%$ of infants were not born in the correct facility, and these infants were also less likely to receive other evidence-based practices such as antenatal corticosteroids, prevention of hypothermia, early surfactant, or continuous positive airway pressure use $\mathrm{s}^{4}$.

\section{Ex utero versus in utero transfer}

There is broad consensus favouring birth in units with appropriate NICU expertise for very premature infants, but when mothers present elsewhere does transfer before or after birth make such a difference? Comparison of ex utero transfer (usually immediate but may be up to 48 hours postnatally) and in utero transfer is usually achieved by retrospective comparison of outcomes of NICU infants born in-house compared with those transferred in. Most studies confirm reductions in morbidity and mortality with in utero versus ex utero transfer, ${ }^{9,12}$. In a recent UK population study, which compared infants born before 28 weeks' gestation $(n=17,577)$, the 2,158 infants transferred within 48 hours of birth to a level 3 unit had no significant difference in the odds of death before discharge (odds ratio [OR] 1.22 , 95\% CI 0.92-1.61) but significantly higher odds of severe brain injury (OR 2.32, 95\% CI 1.78-3.06; NNT 8) and significantly lower odds of survival without severe brain injury (OR 0.60, 95\% CI 0.47-0.76; NNT 9) .

A Canadian national cohort of 28 tertiary neonatal units between 2009 and 2011 reported an excess mortality associated with being transferred ex utero (OR 1.33, CI 1.03-1.77) ${ }^{12}$. Another North American study of in utero compared with ex utero transfers reported statistically significant increases in the incidence of respiratory distress syndrome, bronchopulmonary dysplasia, intraventricular haemorrhage, and mortality $(P=0.001)^{13}$. In a subanalysis of the Swedish population's level 3 neonatal units, the extremely low birth weight infants who were ex utero transfers had a significantly higher mortality than those who were transferred in antenatally ( $42 \%$ versus $26 \%$, adjusted OR 2.8, CI 1.3-5.7 $)^{11}$. However, these benefits are not found across all study populations. In an Australian cohort, there was not a significant difference in mortality within the subset of infants admitted to NICU (29\% of ex utero transfer infants died within 1 year versus $20 \%$ inborn $)^{10}$. In the EPICURE 2 study, an increased number of babies were transferred within 24 hours of birth, but transfer was not associated with an excess morbidity (unlike in the first EPICURE study cohort). The authors suggest that these improvements may reflect improved, but very costly, neonatal transport services ${ }^{14}$.

The limitation with many of these retrospective studies is that they include only those who survive to transfer and reach a level 3 NICU, excluding antenatal deaths and deaths before transfer (survival bias). This does not then represent the real impact of an inability to perform in utero transfer. An excess of deaths prior to transfer from level 1 or 2 settings is missed by analysing NICU data alone, creating a bias against in utero transfer. For example, the EPICURE 2 cohort's antenatal foetal deaths (32\% mortality in level 1 units versus $15 \%$ in level 3) contribute significantly to the UK perinatal mortality ${ }^{1}$. Mothers of extreme preterm infants born in the appropriate setting benefit from tertiary obstetric input and expert delivery room resuscitation. There were significantly more delivery room deaths in level 2 units compared with level 3 units $(17 \%$ versus $7 \%$, aOR 1.67, CI 1.02-2.72). Lower mortality rates may be associated with greater obstetric expertise at these units, such as appropriate steroid administration and skilled caesarean delivery of the preterm breech. The finding that more women received appropriate antenatal corticosteroid administration in higher-level units supports this assumption ${ }^{1}$. The contribution of pre-transfer deaths was recognised by Boland et al., who suggested that the perceived poor prognosis at earlier gestations was likely to have prohibited decisions to transfer in referring units (which in fact had a $69 \%$ chance of survival if admitted to NICU); in effect, these babies were not given the same chance to survive ${ }^{10}$.

For the reasons outlined, short of randomising infants to in utero or ex utero transfer at the point of need for level 3 care is identified (which is both unethical and unfeasible), the true risk of postnatal transfer may be underestimated by some studies. Short of randomized controlled trials (RCTs), propensity score matching to equal the critical background factors in the comparison of outcomes of infants born in different level units is one 
method of adjusting for these effects, as in the recent UK population study ${ }^{9}$. Given the substantial evidence regarding mortality and morbidity excess of ex utero versus in utero transfer and the consensus regarding improved outcomes for those successfully transferred antenatally, compared with those not transferred at all, in utero transfer clearly remains the safest policy for women at risk of preterm birth, particularly at early gestation.

\section{Challenges of in utero transfer}

\section{Which mothers need transfer?}

Pregnant women who require in utero transfer should be considered to be at high risk of delivery within 7 days for the reasons outlined in Figure 1.

Whilst birth in a NICU centre is clearly optimal at extremely preterm gestations, mothers who are medically unstable (e.g. due to placental abruption or eclampsia) or present in advanced preterm labour are not suitable for ambulance travel owing to the risk of suboptimal clinical monitoring during transfer. Since the maternal risk prevents the transfer of the foetus to an appropriate neonatal facility, such emergency presentations are less likely to receive timely antenatal corticosteroids and are associated with adverse neonatal outcomes. It may be argued, therefore, that these "too unstable to transfer" cases may be responsible for the excess in mortality at services with lower-level neonatal services. Analysis of reasons for transfer render this explanation unlikely because preterm birth and preterm prelabour ruptured membranes are much more common indications than acute maternal conditions ${ }^{15}$. Furthermore, the high-risk pregnancies most likely to suffer these obstetric complications are over-represented at tertiary (rather than secondary) services because of antenatal referral processes ${ }^{16}$. In summary, whilst a few of the sickest babies may not be transferred, this is unlikely to wholly account for the substantial excess risk of being born in the "wrong place".

It is, however, critical to reach consensus regarding who is unsuitable for transfer to deliver equitable care to families and to improve transfer processes. Suggested contra-indications collated from UK guidelines are outlined in Figure $2^{17,18}$. It is

\section{Indications for in utero transfer}

- Maternal medical or surgical condition requiring tertiary level input

- Foetal medical or surgical condition requiring iatrogenic delivery at tertiary centre with facilities and capacity for neonatal management, including for any diagnosed subspecialty condition (e.g. cardiac)

- High risk of spontaneous or iatrogenic birth in a unit without facility or capacity to manage the newborn (usually due to prematurity) as per national service specification $[16,17,45]$

Figure 1. Indications for in utero transfer. This figure was adapted from a previous publication by the authors ${ }^{17}$ with permission from London Neonatal Operational Delivery Network.

\section{Women unlikely to be suitable for in utero transfer}

- Pregnancy less than 22 weeks' gestation for foetal reasons

- Potentially lethal foetal condition where active intervention of the foetus was not being considered even if live born (in cases of foetal abnormalities, it is useful to discuss these cases with foetal medicine specialists and the regional neonatal intensive care unit)

- Active labour where the cervix is more than $3 \mathrm{~cm}$ dilated

- Maternal condition that may require intervention during transfer, e.g. antepartum haemorrhage or uncontrolled hypertension

- Known maternal or foetal compromise requiring immediate delivery, including abnormal cardiotocograph

Figure 2. Contra-indications for in utero transfer. This figure was adapted from a previous publication by the authors ${ }^{17}$ with permission from London Neonatal Operational Delivery Network. 
recognised that these are context dependent; longer distances or more limited ambulance resources in different settings are likely to impact acceptable levels of risk for in utero transfer.

\section{Inappropriate in utero transfers}

Having explored the significance of in utero transfers for those who need them, we must also consider inappropriate in utero transfers. Between 50 and $80 \%$ of in utero transfers do not subsequently require neonatal specialist $\mathrm{care}^{15}$. These unnecessary transfers primarily comprise women in threatened preterm labour (TPTL) ${ }^{19}$. If based on symptoms alone, more than $90 \%$ of women transferred for TPTL will not deliver imminently ${ }^{20,21}$, so transferring everyone at early gestations in TPTL $^{17}$ would put additional strain on an imperfect system and endanger successful transfer of those who most need it. In addition, excessive in utero transfers could mean that neonatal cots will be harder to find because tertiary units will be unnecessarily "reserving cots" for their own women in false labour. In practice, in utero transfers are not performed for all women in TPTL, but aside from National Institute for Health and Care Excellence (NICE) guidelines ${ }^{22}$, there is little guidance on what an appropriate threshold should be.

A number of predictive tests are available, but only cervicovaginal foetal fibronectin (fFN) measurement and transvaginal ultrasound cervical length measurements demonstrate high predictive performance in robust trials and are recommended by $\mathrm{NICE}^{22-24}$. Few predictive tests have been clinically evaluated directly in relation to in utero transfer. Given the low population and vast distance between hospitals, it is not surprising that Australian research groups have prioritised this issue. As described by Giles et al., in New South Wales, transfers may involve up to a 4-hour air ambulance flight $(814 \mathrm{~km})$ and a much higher risk of delivery is felt to warrant transfer (up to $50 \%)^{25}$. This group evaluated the use of qualitative fFN as part of clinical examination in their network over a 2-year period; $98.1 \%$ of patients with a closed cervix and a negative fFN did not deliver within 7 days. Importantly, the two women who delivered within 5 days were correctly transferred on the basis of continuing additional symptoms. This study achieved a $51 \%$ reduction in transfers. Reduction in transfers saved $\$ 153,120$ (approximately $£ 85,000$ ), and a reduction in average hospital stay saved an additional $\$ 2,970$ (approximately $£ 1,640$ ) per patient ${ }^{25}$.

The QUiPP app is a decision-making tool that provides an individualised percentage risk of delivery (e.g. within 7 days) that is relevant to in utero transfer decisions (https://quipp. org/). QUiPP improves the prediction of preterm birth by combining individual pregnancy characteristics and the continuous variables of quantitative fFN and/or cervical length measurements to better assess risk ${ }^{26,27}$. Relative to NICE guidance, it can reduce up to $89 \%$ of transfers for women who present prior to 30 weeks' gestation at hospitals without a NICU ${ }^{28}$. Its effectiveness at influencing in utero transfer decisions is currently under evaluation ${ }^{29}$.

What is the burden of in utero transfers on the NHS? Unfortunately, there are no UK-wide data on the prevalence of in utero transfers. An audit of activity in Greater Manchester reported an incidence of 8.5 in utero transfers per 1,000 deliveries $^{19}$. In London, when urgent neonatal transfer requests increased between 2001 and 2004, there was a significant decrease in antenatal transfer requests (relative risk [RR] 0.60, $P<0.01)$ and an increase in ex utero transfers, which has been attributed to the introduction of a centralised neonatal transport service in 2003, creating complacency regarding the urgency of in utero transfers ${ }^{30}$. Data provided from the Emergency Bed Service (who provide assistance with cot location in London) suggest that in utero transfer requests declined from over 100 /month in 2004 to 68 /month in $2012^{31}$.

NHS Scotland conducted a national review of all of its in utero transfers over a 6-month period. There were a total of 599 in utero transfers, $72 \%$ of which were from community maternity units to consultant-led units and $28 \%(\mathrm{n}=165)$ were from consultant-led units to consultant-led units, half of which $(\mathrm{n}=86)$ were between tertiary units ${ }^{32}$. The high contribution of in utero transfers for capacity rather than expertise is widespread in the UK. Such transfers may be associated with less excess morbidity and mortality but still entail significant stress and cost for the parents. Transfers for expertise are inevitable with neonatal subspecialisation, but transfers due to capacity alone are indicative of a dysfunctional over-stressed system.

By definition, in utero transfer is difficult to evaluate and organise owing to reporting systems and clinical pathways that do not cross providers or specialties (obstetrics, midwifery, and neonatology) adequately. The lack of ownership around this challenging process has no doubt contributed to the lack of progress in improving the system in recent decades. However, recent NICE preterm birth guidance advises that all women in TPTL who are $<30$ weeks' gestation should be transferred to units with appropriate neonatal expertise (without the use of predictive tests) ${ }^{16,22}$. If widely adopted, this guidance will dramatically increase the total number of in utero transfers, without prudent prioritisation of the most important ones.

Transfers are time-consuming and costly because of inefficient transfer processes. In the London Neonatal Transport Teams' detailed analysis of in utero transfers, $47 \%(158 / 338)$ of referrals to the emergency bed service were not successful, and 11/69 postnatal transfers prior to 29 weeks' gestation were identified as failed in utero transfers. Clinicians spent a median (interquartile range) of 240 (150-308) minutes contacting seven (6-8) units when trying to arrange transfers ${ }^{33}$. The high occupancy levels of neonatal units and the shifting capacity of maternity units are cited as the primary reasons for difficulty in locating a suitable unit to refer to ${ }^{24,25}$. A lack of utilisation of technology or a unified referral process compound this problem according to a UK survey of clinicians involved in this process ${ }^{31}$. In the North West region, where a dedicated cot bureau exists, the three most common reasons for failed in utero transfers were a lack of maternal beds (29\%), a lack of cots (23\%), and transfer deemed inappropriate following consultant-toconsultant discussion $(26 \%)^{19}$.

The administrative burden and pathway variation of in utero transfer risk compromising the quality of clinical care. Antenatal 
corticosteroid administration is likely to have optimal impact on reducing neonatal mortality and respiratory distress syndrome if given between 24 hours and 7 days of delivery ${ }^{34,35}$. In the context of in utero transfer, it is common for the first dose to be delayed until the mother reaches the receiving unit and for steroid courses to be incomplete because of communication failures ${ }^{19}$.

\section{Impact of in utero transfers on women}

It is well recognised that the transfer of babies in the early neonatal period is a frightening and stressful experience for parents $^{35}$. The loss of familiarity and separation from their vulnerable child at a critical stage when bonds are being established represent a disruption in their parenthood, which can impair the health and development of the infant ${ }^{37}$. It is important to emphasise that for parents whose babies are delivered immediately after transfer, the in utero experience avoids separation from the baby and is preferable to a postnatal transfer. However, transfers before birth are also associated with emotional and financial burden upon the women and their families because of longer travel distances between home and their newborn. Broadly, women recognise the importance of in utero transfer and find it acceptable ${ }^{15,38}$. However, the unplanned relocation to unfamiliar surroundings at an already stressful time in the pregnancy creates anxiety, shock, and worry ${ }^{38}$. The emotional and financial burden of in utero transfers upon women and their families is beginning to be explored in the literature, such as the following description of a woman who was transferred from her home hospital because of capacity issues:

"A nightmare. Not something I'd like to relive. Because although there wasn't massive complications or anything, I got really stressed because I didn't know what was going to happen... And I think it's quite annoying, because I think me and my partner spent quite a lot of time getting annoyed, thinking why couldn't he have just stayed at XXX" ${ }^{\prime 38}$.

Pregnant women value choice of birth place and continuity of care as important aspects of their care ${ }^{39}$, and in utero transfer can feel like the antithesis of this. The loss of choice and control associated with relocation may be driven by local cultural identities as much as inconvenience ${ }^{40}$.

There is also considerable anxiety around domestic and logistical issues. Separation from children left at home is one of the most difficult aspects reported, and many perceived a particularly negative and unrecognised impact on their partners ${ }^{38}$. The travel costs, excess phone bills, accommodation, and unpaid leave for partners add up to considerable financial strain. The excess strain of being transferred elsewhere compared to a local admission for TPTL would benefit from a direct comparison of women's experiences, as some of the domestic and financial issues would be incurred with any admission during pregnancy.

Given that stress is a known predictor of adverse pregnancy outcomes $^{41,42}$, the excess anxiety caused by transfer may have a negative impact on both mother and baby. Some of the qualitative studies allude to methods by which we could improve the in utero transfer process for women, such as improved communication or financial remittance to transferred women ${ }^{38}$. Therefore, improving TPTL risk assessment and in utero transfer pathways may help in shared decision-making regarding the need for in utero transfer and have a significant impact in reducing the anxiety of the whole experience. Critically, for families whose infants do not go on to deliver imminently, better selection of the most appropriate women for transfer would avoid the parental strain of in utero transfer altogether for some families.

\section{Reforming the in utero transfer process}

The negative impact on women's pregnancy experiences, inappropriate selection of the right women to transfer, and high administrative costs all demand time for change.

\section{Learning from others: centralised transfer services}

Following their comprehensive audits of the problem, cot bureaus have been established in some regions of the $\mathrm{UK}^{19,32,43}$. As well as regularly phoning neonatal units to check cot status, the cot bureaus liaise with neonatal and maternity teams to arrange referrals for particular requests. Centralising the referrals reduces the clinical time spent on organising transfer, establishes a unified process across hospitals, and is likely to create efficiencies due to developing expertise in the problem. However, even within these dedicated services, around one-third of transfer requests are unsuccessful because of capacity issues, withdrawal of requests, or a lack of consensus on the appropriateness of the in utero transfer ${ }^{20,33,43}$. This suggests culture change amongst referrers and receivers of in utero transfers is needed in addition to further investment in capacity.

Centralisation of perinatal services to five tertiary centres in Finland from 1999 to 2017 has been associated with increases in survival of very preterm infants ( $<32$ weeks' gestation) from $72 \%$ in 1987 to over $90 \%$ since 2012. This has been achieved with a very low rate of ex utero transfers (2-4\% of all very preterm infants) ${ }^{8}$. How this was achieved may be linked with the Finnish national birth register, which empowers clinicians to implement evidence-based change from the high-quality data they themselves have generated ${ }^{8}$. The smaller population, and a well-funded government health system, may also facilitate centralising expertise and strike a contrast with the UK.

This differs to Australia, where variations in resources and geography are more profound. Policy makers have decided to prioritise the issue of in utero transfer in this setting. State- and territory-wide policies vary slightly according to local resources and distance to referring hospitals but differ little on risk stratification and management. The common theme amongst the more streamlined services is a centralised coordinated approach. Victoria utilise the Paediatric Infant Perinatal Emergency Retrieval (PIPER) service. They offer a one-point-of-contact 24-hour emergency conference line involving a dedicated PIPER neonatal consultant and retrieval team. The team provide advice where required, organise an appropriate referral site, and mobilise a team for transfer. Queensland transfers are facilitated by Retrieval Services Queensland (RSQ), who provide a 
24-hour call service dedicated to identifying suitable accepting units and initiate a conference call between referring and accepting obstetric teams ${ }^{44}$.

Rural Western Australia has only one tertiary referral hospital serving an area of over 2.5 million square kilometres, so aeromedical retrieval is the preference for the vast majority of in utero transfers. Interestingly, there has never been a preterm delivery mid-flight despite women regularly being transferred in established preterm labour. The possible effect of ambient altitude and cabin pressure on delaying preterm delivery has been hypothesised as a possible explanation for this ${ }^{33}$.

\section{Changing policy in the UK}

Following extensive stakeholder collaboration, an NHS England pan-London working party on in utero transfer concluded that improved, unified data collection across the region was a key target and an in utero transfer record was created for this purpose (see Figure 3$)^{17}$. The goal of this regional guideline is to better inform clinicians, support their decision-making process, and reduce inappropriate variation in practice. A core theme across the recommendations was to change the culture around the perception of in utero transfers being "not my problem" and encouraging an opt-out rather than an opt-in approach. For example, a lack of a readily available bed on the labour ward ought not always to preclude transfer, as co-ordinators are adept at directing the flow of women through maternity services and many women could transfer to an antenatal ward initially.

The objectives and recommendations of this London-based guideline might provide a useful template for other UK regions, although variations in networks, resources, and geography would require that the creation of a national in utero transfer guideline had extensive stakeholder involvement, including patients and their families. For example, NHS Scotland's in utero transfer review prompted staffing reviews across all level 3 units and recommendations regarding the use of tocolytic therapy and the use of predictive tests to accurately diagnose preterm labour. This was aligned with their centralised system to identify available beds ${ }^{32}$.

\section{Technological solutions}

Whilst improving transfer protocols and inter-hospital pathways is fundamental to addressing problems with in utero transfer, a 2013 survey of UK clinicians found that a lack of utilisation of technology was viewed as a significant contributor to low success rates $^{31}$. Technological solutions can offer a real-time transparent overview of cot availability facilitating centralised coordination of neonatal services. In Australia, New South Wales Health have pledged $\$ 1.5$ million $(£ 842,000)$ to enhance current transfer processes. In addition to provision of a 24/7 perinatal advice line, the Maternal Transfers Redesign Project plans to implement an Electronic Patient Journey Board with maternity

1. All potential transfers must be authorised by the on-call obstetric consultant following discussion with the consultant neonatologist/paediatrician of the referring hospital

2. Maternal agreement needs to be obtained prior to transfer

3. There should be one point of contact (neonatal unit) at the receiving unit to minimise burden of phone calls

4. There is an expectation that a receiving hospital with neonatal intensive care unit will accept an appropriate in utero referral from a special care unit (SCU) or local neonatal unit within their network unless there are exceptional circumstances

5. It is the responsibility of the receiving neonatal AND obstetric team to agree or refuse transfer within one hour of referral

6. A decision of the potential receiving neonatal team to refuse acceptance of an appropriate transfer should be made only after consultation with the neonatal consultant in charge

7. A decision of the potential receiving maternity unit to refuse transfer should be made only after consultation between the midwife in charge of the labour ward and the obstetric consultant on duty or on call

8. All clinical involvement with any attempted in utero transfers should be recorded and available for clinical audit

9. As a minimum, Local Maternity Systems and the Neonatal Operational Delivery Network should audit the number of admitted babies born at less than 27 weeks of gestation delivered in maternity services who are not on the same site as a designated neonatal intensive care unit

Figure 3. Main messages and recommendations reported in the Pan-London In Utero Transfer Guidance: Changing the Conversation. This figure was adapted from a previous publication by the authors ${ }^{17}$ with permission from London Neonatal Operational Delivery Network. 
and neonatal functionality. The system will provide a real-time dashboard allowing for allocation and monitoring of maternity and neonatal beds across the state.

The Scottish "Scotstar" neonatal transport system co-ordinates in utero transfer requests alongside ex utero perinatal transfer requests across Scottish neonatal networks (https://www.neonataltransport.scot.nhs.uk). Having taken the clinical details from the referrer, the cot bureau uses BadgerNet cot locator to identify likely cot availability before contacting units. Scotland's uptake of the BadgerNet maternity platform as well as the neonatal platform enhances continuity between obstetric and neonatal events, such as transfer, relative to less compatible digital systems. As the BadgerNet software is now utilised for computerised neonatal records in 250 hospitals across the UK, Australia, and New Zealand, there are significant synergies from using an already acceptable and integrated platform.

With the advent of smartphones, there is the potential to deliver in utero transfer reform from the palm of the clinician's hand. Conceived and created by UK obstetric and gynaecology junior doctors, a free android app, iOS app, and website is now available to streamline the in utero transfer process using GPS technology and neonatal network algorithms to provide a live database of cot availability in the surrounding hospitals (https://www.cotfinder.com/) (Figure 4). Search results are arranged in order of relevance (network, expertise), and the relevant contact details of both the neonatal unit and the maternity unit are provided. It also has the capability to record requests, tests, and outcomes to ease future audit of this problem.

If commitments to update the cot status can be secured, CotFinder has the potential to transform the ease and success of in utero transfer throughout the UK and beyond.

CotFinder's appropriateness has been confirmed by $100 \%$ daily updates in South London Neonatal Operational Delivery Network following roll-out in August 2019. However, its successful wider adoption depends on a cultural shift towards greater shared responsibility and investment in this issue.

\section{Conclusion}

In utero transfer is an unavoidable aspect of maternity and neonatal care, the burden of which is likely to increase if preterm birth rates rise, attitudes change towards viability at thresholds of survival, and health services continue to face funding pressures. Competing inter-disciplinary tensions between valid concerns for neonatal wellbeing and the risks and burden of both necessary and unnecessary transfer have led to inconsistent

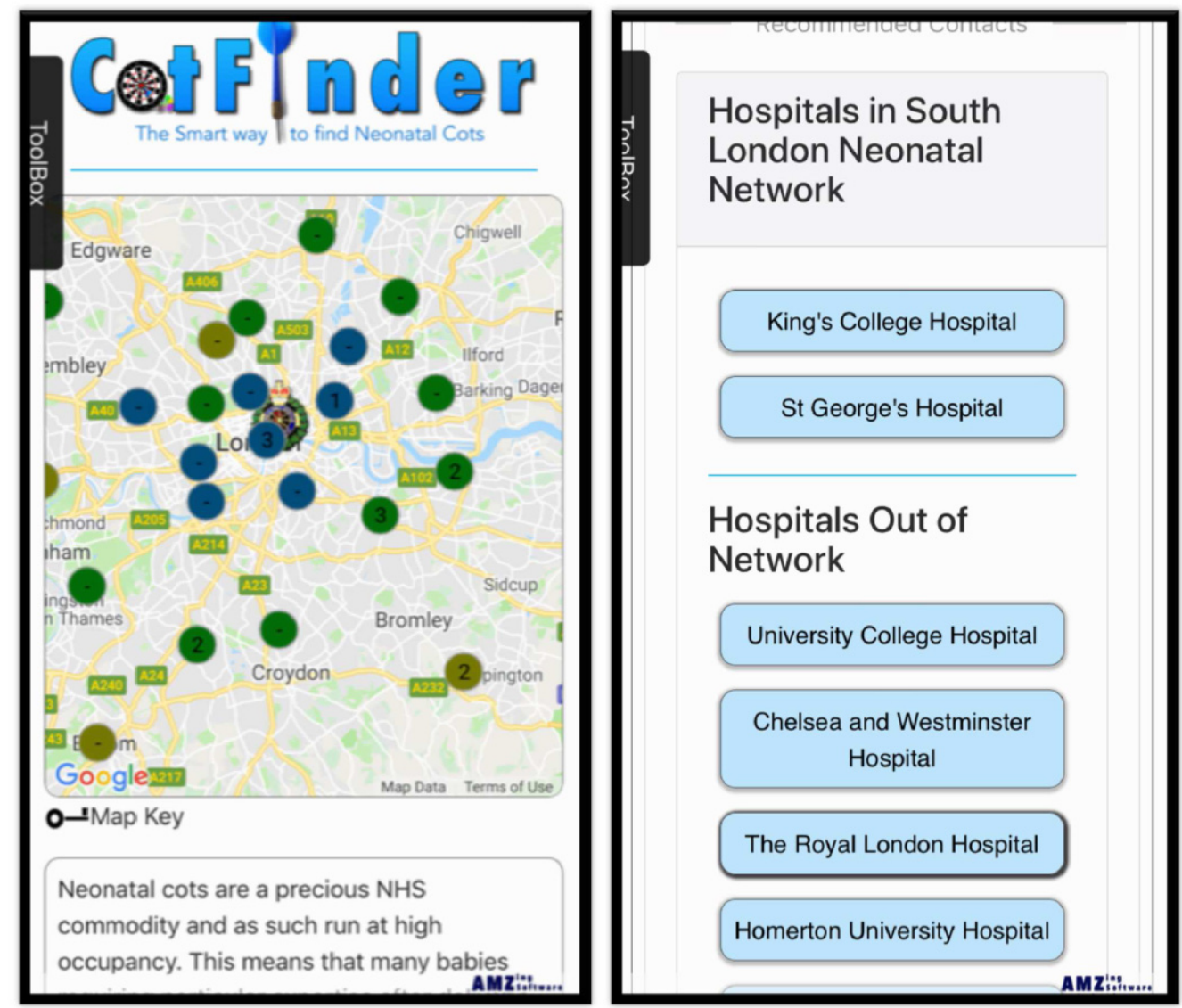

Figure 4. CotFinder app screenshots. 
practices. Policy reform of inter-hospital transfers needs to be regional, if not national, by definition. Emerging change in attitudes to this shared responsibility coupled with technological innovation offer real promise for transformation. By better prioritisation of in utero transfers, obstetric teams have an opportunity to demonstrate how far their advocacy for pregnant women and their babies goes beyond the delivery room. Sustained multi-disciplinary commitment with buy in from obstetric, midwifery, and neonatal teams is crucial to effective planning for preterm delivery to maximise good outcomes.
1. Mactier $\mathrm{H}$, Bates $\mathrm{SE}$, Johnston $\mathrm{T}$, et al:: Perinatal management of extreme preterm birth before $\mathbf{2 7}$ weeks of gestation: A framework for practice. Arch Dis Child Fetal Neonatal Ed. 2020; 105(3): 232-9.

PubMed Abstract | Publisher Full Text | Faculty Opinions Recommendation

2. Marlow N, Bennett C, Draper ES, et al.: Perinatal outcomes for extremely preterm babies in relation to place of birth in England: The EPICure 2 study. Arch Dis Child Fetal Neonatal Ed. 2014; 99(3): F181-8. PubMed Abstract | Publisher Full Text | Free Full Text | Faculty Opinions Recommendation

3. Lee SK, McMillan DD, Ohlsson A, et al.: The benefit of preterm birth at tertiary care centers is related to gestational age. Am J Obstet Gynecol. 2003, 188(3): 617-22.

PubMed Abstract | Publisher Full Text

4. Zeitlin J, Manktelow BN, Piedvache A, et al.: Use of evidence based practices to improve survival without severe morbidity for very preterm infants: Results from the EPICE population based cohort. BMJ. 2016; 354: i2976.

PubMed Abstract | Publisher Full Text | Free Full Text | Faculty Opinions Recommendation

5. Lasswell SM, Barfield WD, Rochat RW, et al.: Perinatal regionalization for very low-birth-weight and very preterm infants: A meta-analysis. JAMA. 2010; 304(9): 992-1000.

PubMed Abstract | Publisher Full Text

6. Rautava L, Lehtonen L, Peltola M, et al.: The Effect of Birth in Secondary- or Tertiary-Level Hospitals in Finland on Mortality in Very Preterm Infants: A Birth-Register Study. Pediatrics. 2007; 119(1): e257-e263. PubMed Abstract | Publisher Full Text

7. NHS England service specifications. Reference Source

8. Helenius K, Gissler M, Lehtonen L: Trends in centralization of very preterm deliveries and neonatal survival in Finland in 1987-2017. Trans/ Pediatr. 2019; 8(3): 227-32.

PubMed Abstract | Publisher Full Text | Free Full Text | Faculty Opinions Recommendation

9. Helenius K, Longford N, Lehtonen L, et al.: Association of early postnatal transfer and birth outside a tertiary hospital with mortality and severe brain injury in extremely preterm infants: Observational cohort study with propensity score matching. BMJ. 2019; 367: I5678. PubMed Abstract | Publisher Full Text | Free Full Text | Faculty Opinions Recommendation

10. Boland RA, Davis PG, Dawson JA, et al.: Outcomes of infants born at 22-27 weeks' gestation in Victoria according to outborn/inborn birth status. Arch Dis Child Fetal Neonatal Ed. 2017; 102(2): F153-F161.

PubMed Abstract | Publisher Full Text | Faculty Opinions Recommendation

11. Finnström $O$, Olausson PO, Sedin G, et al.: The Swedish national prospective study on extremely low birthweight (ELBW) infants. Incidence, mortality, morbidity and survival in relation to level of care. Acta Paediatr. 1997; 86(5): 503-11.

PubMed Abstract | Publisher Full Text

12. Synnes A, Luu TM, Moddemann D, et al.: Determinants of developmental outcomes in a very preterm Canadian cohort. Arch Dis Child Fetal Neonatal Ed. 2017: 102(3): F235-F234.

PubMed Abstract | Publisher Full Text | Faculty Opinions Recommendation

13. Shlossman PA, Manley JS, Sciscione AC, et al.: An Analysis of Neonatal Morbidity and Mortality in Maternal (In Utero) and Neonatal Transports at 24-34 Weeks' Gestation. Am J Perinatol. 1997; 14(8): 449-56. PubMed Abstract | Publisher Full Text

14. Costeloe KL, Hennessy EM, Haider S, et al.: Short term outcomes after extreme preterm birth in England: Comparison of two birth cohorts in 1995 and 2006 (the EPICure studies). BMJ. 2012; 345: e7976. PubMed Abstract | Publisher Full Text | Free Full Text

15. Bond PA, Crisp AS, Morgan MEI, et al.: Maternal attitudes to transfer before delivery. Journal of Reproductive and Infant Psychology. 2007; 2(1): 33-41. Publisher Full Text

16. National Institute for Health and Care Excellence: Antenatal care for uncomplicated pregnancies. Clin Guidel. 2008

Reference Sourc

17. Pan-London in utero transfer working party: Pan-London Guideline for In Utero Transfer - London Clinical Networks. NHS London Clinical Netowkrs. 2018.

Reference Source

18. Fenton A, Peebles D, Ahluwalia J: Management of acute in utero transfers: a framework for practice. Rep Br Assoc Perinat Med. 2008. Reference Source

19. Greater Manchester Neonatal Transport Service (GMNeTS) Interim Annual Report. 2006

Reference Source

20. Peaceman AM, Andrews WW, Thorp JM, et al.: Fetal fibronectin as a predictor of preterm birth in patients with symptoms: A multicenter trial. Am J Obstet Gynecol. 1997; 177(1): 13-8. PubMed Abstract | Publisher Full Text

21. Honest $\mathrm{H}$, Hyde $\mathrm{CJ}$, Khan KS: Prediction of spontaneous preterm birth: No good test for predicting a spontaneous preterm birth. Curr Opin Obstet Gynecol. 2012; 24(6): 422-33. PubMed Abstract | Publisher Full Text

22. National Collaborating Centre for Women's and Children's Health (UK): Preterm Labour and Birth. Natl Inst Heal Care Excell. 2015; November. PubMed Abstract

23. Abbott DS, Radford SK, Seed PT, et al.: Evaluation of a quantitative fetal fibronectin test for spontaneous preterm birth in symptomatic women. $A m$ J Obstet Gynecol. 2013; 208(2): 122.e1-122.e6.

PubMed Abstract | Publisher Full Text

24. Tsoi E, Akmal S, Geerts L, et al.: Sonographic measurement of cervical length and fetal fibronectin testing in threatened preterm labor. Ultrasound Obstet Gynecol. 2006; 27(4): 368-72.

PubMed Abstract | Publisher Full Text

25. Giles W, Bisits A, Knox M, et al.: The effect of fetal fibronectin testing on admissions to a tertiary maternal-fetal medicine unit and cost savings. $A m$ J Obstet Gynecol. 2000; 182(2): 439-42.

PubMed Abstract | Publisher Full Text

26. Kuhrt K, Hezelgrave N, Foster C, et al.: Development and validation of a tool incorporating quantitative fetal fibronectin to predict spontaneous preterm birth in symptomatic women. Ultrasound Obstet Gynecol. 2016; 47(2): 210-6.

PubMed Abstract | Publisher Full Text

27. Watson HA, Seed PT, Carter J, et al.: Development and validation of predictive models for QUiPP App v.2: Tool for predicting preterm birth in asymptomatic high-risk women. Ultrasound Obstet Gynecol. 2020; 55(3): 348-56.

PubMed Abstract | Publisher Full Text

28. Watson HA, Carter J, Seed PT, et al.: The QUiPP App: A safe alternative to a treat-all strategy for threatened preterm labor. Ultrasound Obstet Gynecol. 2017; 50(3): 342-6.

PubMed Abstract | Publisher Full Text

29. Watson HA, Carlisle N, Kuhrt K, et al.: EQUIPTT: The Evaluation of the QUiPP app for Triage and Transfer protocol for a cluster randomised trial to evaluate the impact of the QUiPP app on inappropriate management for threatened preterm labour. BMC Pregnancy Childbirth. 2019; 19(1): 68. PubMed Abstract | Publisher Full Text | Free Full Text

30. Kempley ST, Baki Y, Hayter G, et al.: Effect of a centralised transfer service on characteristics of inter-hospital neonatal transfers. Arch Dis Child Fetal Neonatal Ed. 2007; 92(3): F185-8.

PubMed Abstract | Publisher Full Text | Free Full Text

31. J M, H W: Survey of current inutero transfer services in England. BJOG An Int J Obstet Gynaecol. 2014.

32. NHS Scotland: ScotSTAR Scottish Neonatal Transport Service - The website of the Scottish Neonatal Transport Service. Reference Source

33. Gale C, Hay A, Philipp C, et al.: In-utero transfer is too difficult: Results from a prospective study. Early Hum Dev. 2012; 88(3): 147-50.

PubMed Abstract | Publisher Full Text 
34. Roberts D, Dalziel S: Antenatal corticosteroids for accelerating fetal lung maturation for women at risk of preterm birth. Cochrane Database Syst Rev. 2006; (3): CD004454.

PubMed Abstract | Publisher Full Text

35. Norman M, Piedvache A, Børch K, et al.: Association of Short Antenatal Corticosteroid Administration-to-Birth Intervals With Survival and Morbidity Among Very Preterm Infants: Results From the EPICE Cohort. JAMA Pediatr. 2017; 171(7): 678-86.

PubMed Abstract | Publisher Full Text | Free Full Text Faculty Opinions Recommendation

36. Aagaard H, Hall EOC, Ludvigsen MS, et al.: Parents' experiences of neonatal transfer. A meta-study of qualitative research 2000-2017. Nurs Inq. 2018; 25(3): e12231.

PubMed Abstract | Publisher Full Text | Faculty Opinions Recommendation

37. Fegran L, Helseth S, Fagermoen MS: A comparison of mothers' and fathers' experiences of the attachment process in a neonatal intensive care unit. J Clin Nurs. 2008; 17(6): 810-6.

PubMed Abstract | Publisher Full Text

38. N Porcellato L, Masson G, O'Mahony F, et al.: 'It's something you have to put up with'-service users' experiences of in utero transfer: A qualitative study. BJOG. 2015; 122(13): 1825-32.

PubMed Abstract | Publisher Full Text | Faculty Opinions Recommendation

39. Bramadat IJ, Driedger M: Satisfaction with childbirth: Theories and methods of measurement. Birth. 1993; 20(1): 22-9.

PubMed Abstract | Publisher Full Text

40. Walker J: Women's experiences of transfer from a midwife-led to a consultant-led maternity unit in the UK during late pregnancy and labor. J Midwifery Womens Health. 2000; 45(2): 161-8.

PubMed Abstract | Publisher Full Text

41. Latendresse $\mathrm{G}$ : The interaction between chronic stress and pregnancy: Preterm birth from a biobehavioral perspective.J Midwifery Womens Health. 2009; 54(1): 8-17.

PubMed Abstract | Publisher Full Text | Free Full Text

42. Dole N, Savitz DA, Hertz-Picciotto I, et al.: Maternal Stress and Preterm Birth. Obstet Gynecol Surv. 2003; 58(6): 365-6.

Publisher Full Text

43. Cheema IU, Bomont RK: Antenatal maternal transfers in the east of England: Role of a centralised cot bureau. Arch Dis Child Fetal Neonatal Ed. 2006; 91(1): F78.

PubMed Abstract | Publisher Full Text | Free Full Text

44. Akl N, Coghlan EA, Nathan EA, et al.: Aeromedical transfer of women at risk of preterm delivery in remote and rural Western Australia: Why are there no births in flight? Aust N Z J Obstet Gynaecol. 2012; 52(4): 327-33. PubMed Abstract | Publisher Full Text

45. Fenton A, Peebles D: Management of acute in-utero transfers: a framework for practice. J Ahluwalia for BAPM. 2008.

Reference Source 


\section{Open Peer Review}

\section{Current Peer Review Status:}

\section{Editorial Note on the Review Process}

Faculty Reviews are review articles written by the prestigious Members of Faculty Opinions. The articles are commissioned and peer reviewed before publication to ensure that the final, published version is comprehensive and accessible. The reviewers who approved the final version are listed with their names and affiliations.

\section{The reviewers who approved this article are:}

\section{Version 1}

\section{Jennifer Zeitlin}

Obstetrics, Perinatal and Paediatric Epidemiology Research Team, Centre for Epidemiology and Biostatistics (U1153), INSERM and DHU Risks in Pregnancy, Paris-Descartes University, Paris, France Competing Interests: No competing interests were disclosed.

\section{Liisa Lehtonen}

${ }^{1}$ Department of Clinical Medicine, University of Turku, Turku, Finland

2 Department of Paediatrics and Adolescent Medicine, Turku University Hospital, Turku, Finland Competing Interests: No competing interests were disclosed.

The benefits of publishing with F1000Research:

- Your article is published within days, with no editorial bias

- You can publish traditional articles, null/negative results, case reports, data notes and more

- The peer review process is transparent and collaborative

- Your article is indexed in PubMed after passing peer review

- Dedicated customer support at every stage

For pre-submission enquiries, contact research@f1000.com 